\title{
A revised and improved version of the MRP algorithm: Rev MRP
}

\author{
Marco D'Avino ${ }^{1, a}$, Alfredo Bregni ${ }^{2, b}$, Massimiliano Maria Schiraldi ${ }^{3, c}$ \\ 1,3 “Tor Vergata" University of Rome, Department of Enterprise Engineering, \\ via del Politecnico 1, 00133 Rome, Italy \\ ${ }^{2}$ Aerografo SAS, via San Cipriano 28, 00136 Rome, Italy \\ amarco.d.avino@uniroma2.it, ${ }^{b}$ abregni@iperv.it, cschiraldi@uniroma2.it
}

\begin{abstract}
Keywords: MRP nervousness, safety stocks, lot sizing techniques, demand uncertainty, inventory management, forecasts
\end{abstract}

\begin{abstract}
This article illustrates an improvement of the traditional MRP algorithm, providing significant benefits in terms of reducing the nervous behavior, better pacing order releases, lowering inventory and concurrently reducing the need for continuous forecast adjustments. The proposed algorithm uses the same set of MRP formulas but refers to a L4L continuous replenishment / production routine, anyway succeeding in releasing batch orders according to EOQ and/or POQ criteria. Simulations have been performed on a three-echelon supply chain in order to test the algorithm effectiveness, either in case of stable but stochastic demand or in case of sudden surges.
\end{abstract}

\section{Introduction}

The Material Requirements Planning (MRP) basic calculation computes a future projection of the inventory level - on a time horizon at least equal to the total upstream lead-time - by algebraically summing the stock at hand, the planned receipts and the gross requirements coming from the Master Production Schedule (MPS): if, for a certain item, the projected inventory level gets below a predefined threshold (which can eventually include safety stocks), a new procurement or production order is released.

The MRP, first introduced in 1975 [1], exhibits significant downsides:

- infinite capacity hypothesis [2,3];

- parameter-affected computation (e.g. safety stock levels, planned lead time, time fences, planning horizons) $[4,5,6,7,8]$;

- need for final demand forecast and related impacts on inventory costs and shortages [9];

- risk of distortions of the up-stream requirements by the down-stream computations [10,11];

- "nervousness": distorted demand information - combined with forecast updating, order batching, price fluctuations, rationing and shortage gaining - generates the well-known bullwhip effect $[12,13,14]$, which entails large inefficiencies (excessive inventory, poor customer service, lost revenues, misguided capacity plans, ineffective transportation and missed production schedules).

The term "nervousness" was first introduced by Daniel Steele [15] and presented again in several papers [16,17]: it refers to significant changes in the planning order, even in case of minor changes in the higher-level MRP or MPS. Notably, no attention appears to have been given in the known literature to the fact that the MRP algorithm may exhibit nervousness even with no changes in demand at all, except for lot-for-lot lot sizing techniques (the problem, linked to the need to release batch orders, appears in the form of irregular patterns in the order releases).

Several ways have been proposed to reduce nervousness:

- knowledge sharing along the supply chain [9] and management of delayed information [18];

- freezing the schedule within the planning horizon or changing cost procedure $[10,19]$;

- increasing forecasting horizon [20];

- adopting specific lot sizing techniques, e.g. lot for lot $[10,21]$;

- exploiting safety stocks [10]. 
These solutions referred to above, originated excessive costs (e.g. inventory and organizational costs) and make the system inflexible, not suitable to the most end product demands (which may be characterized by high uncertainty due to sudden changes in customer requirements, introduction of new products, etc.).

The algorithm here described (henceforth indicated as Rev. MRP, which stands for "revised MRP") better copes with uncertainty demand, lowers the system nervousness and also removes the need for continuous forecast adjustments, thereby improving the ease in managing the material flow:

- excess nervousness is eliminated, and the order releases pattern made regular, by introducing a simpler and more efficient lot sizing technique;

- inventory levels are reduced;

- the need of stockpiling in up-stream echelons is eliminated, allowing the use of smaller warehouses, with less logistic costs for the whole supply chain;

- there is no need for the MPS to provide a short-term, demand-originated, continuously revised forecast, since the new computation uses the latest demand directly as a short term forecast.

\section{The new algorithm in brief}

Rev MRP operates with more stable behavior and drastically lower stocks than the traditional MRP. Lot for Lot (L4L) technique is seldom applied in practice because of its several drawbacks due to the lack of batch ordering (high ordering costs, poor performance with far-off suppliers, organizational burden due to changing schedules); however, it appears to be much less affected from nervousness and stockpiling-related limitations which characterizes batch-oriented techniques like Economic Order Quantity (EOQ) and Period Order Quantity (POQ).

The new computation approach starts from using the same set of MRP formulas [22] within a L4L continuous replenishment / production context. In other words, for all the echelons it computes L4L "emulated" stock levels, but keeping the actual batch releases outside of the algorithmic loop. Differently from the original MRP, the batch orders are then released by cumulating these emulated L4L orders, according to the desired type of batch: up to a predefined batch size, for fixed batch size orders at variable dates; along a predefined period of time, for variable batch size orders at fixed dates. As a result, the proposed algorithm can release batch orders simulating EOQ and/or POQ criteria, while enjoying the lower nervousness and the reduced level of stocks of the L4L lot sizing technique.

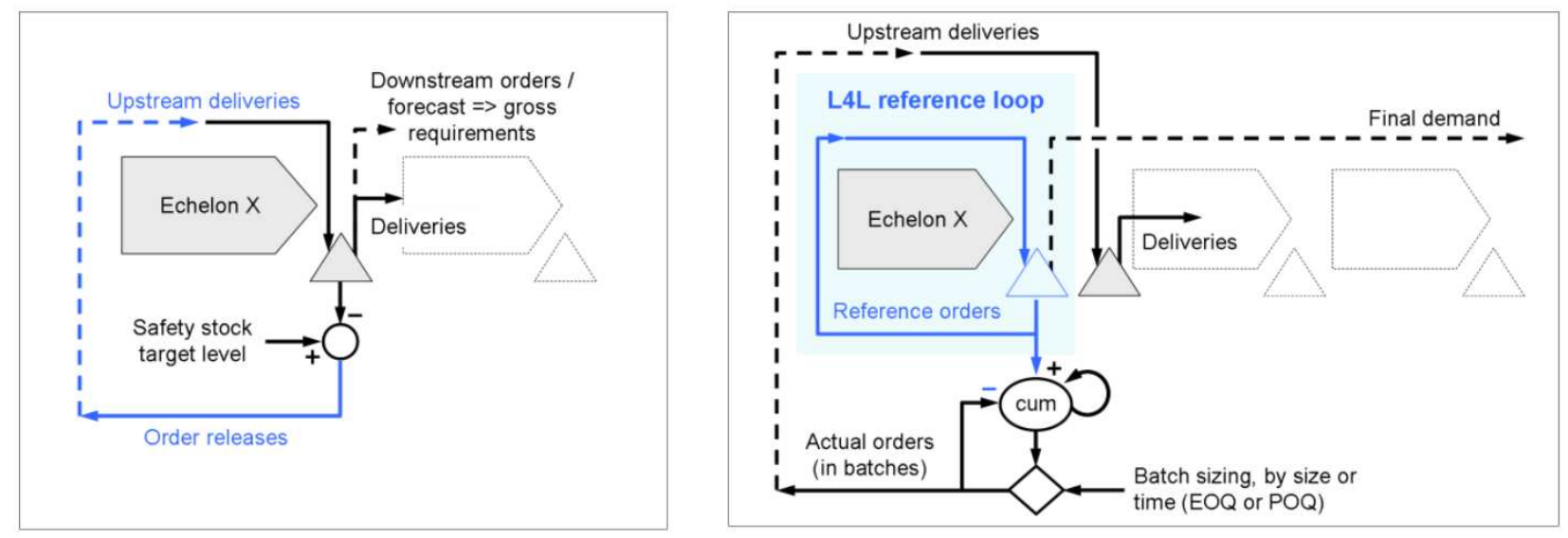

Figure 1: Traditional MRP logic (left) vs Rev MRP logic (right)

\section{Rev MRP in a multi-echelon supply chain}

Simulations have been performed on a three-echelon supply chain, by varying and combining the following parameters:

- final customer demand (deterministic vs uncertain, stable demand vs sudden surges);

- lot sizing techniques (EOQ and POQ);

- delivery lead time. 
In simulations, with respect to the original MRP, the new algorithm showed a significant reduction of the nervous behavior, with better paced order releases (see Figures below), both with stable and varying demand, and lower inventory levels.
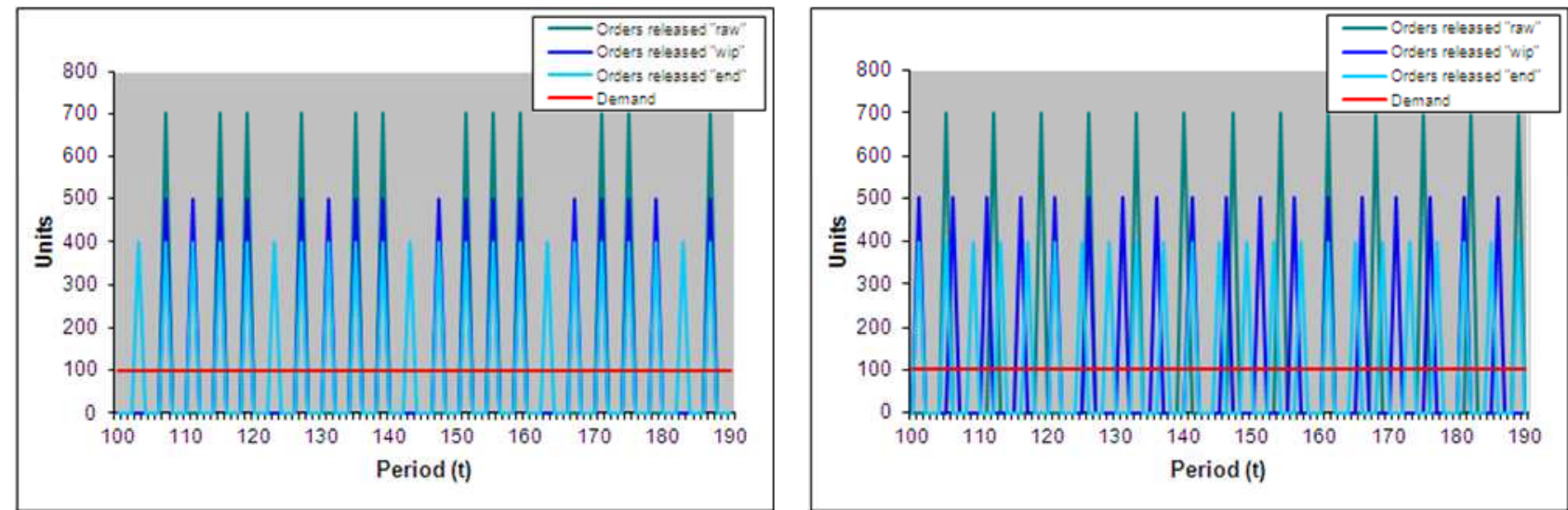

Figure 2: Orders released along the supply chain by traditional MRP (left) and Rev MRP (right): EOQ lot sizing techniques - stable demand
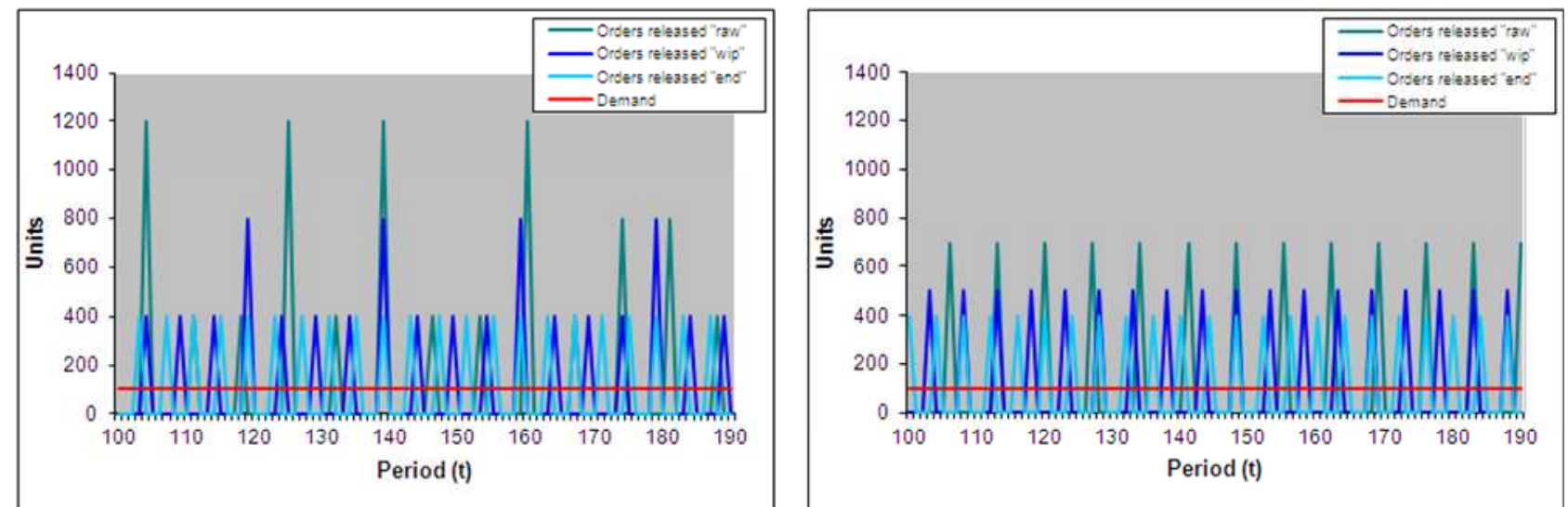

Figure 3: Orders released along the supply chain by traditional MRP (left) and Rev MRP (right): POQ lot sizing techniques - stable demand
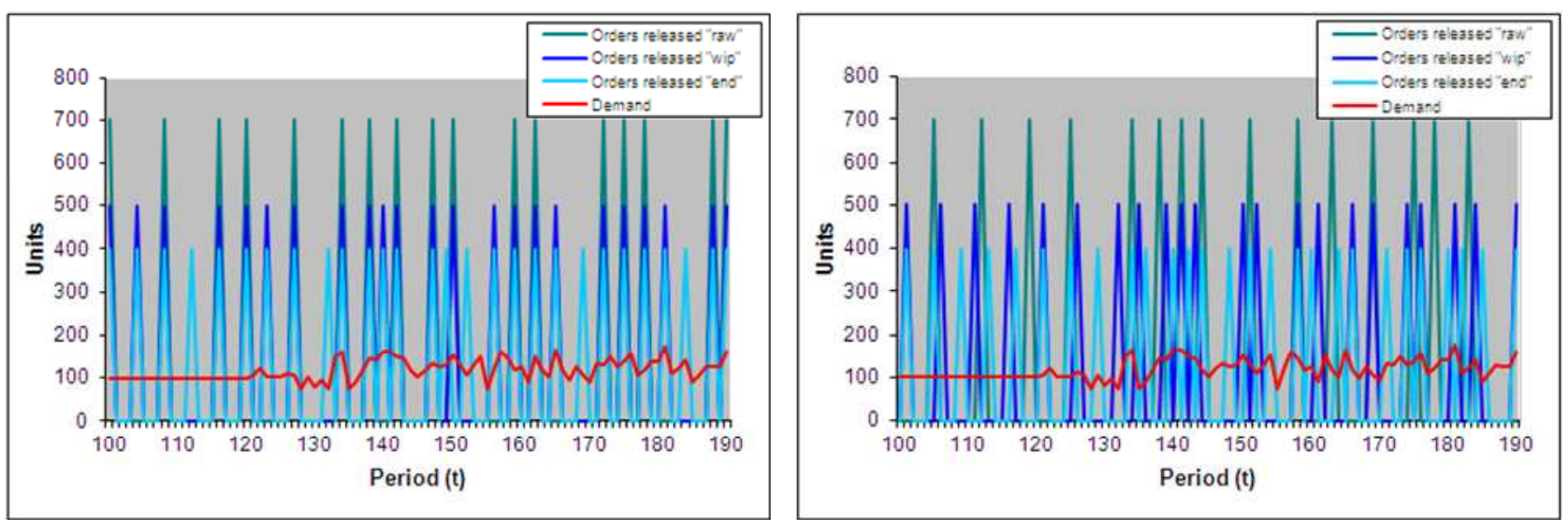

Figure 4: Orders released along the supply chain by traditional MRP (left) and Rev MRP (right): EOQ lot sizing techniques - uncertain demand with a sudden change 

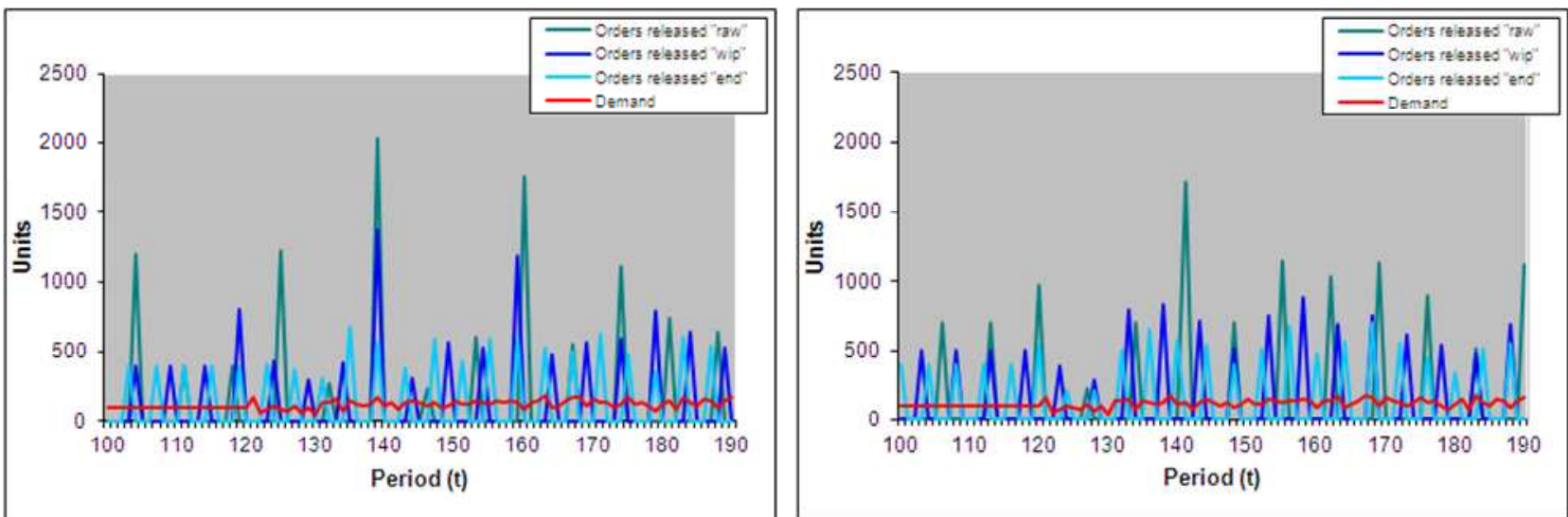

Figure 5: Orders released along the supply chain by traditional MRP (left) and Rev MRP (right): POQ lot sizing techniques - uncertain demand with a sudden change

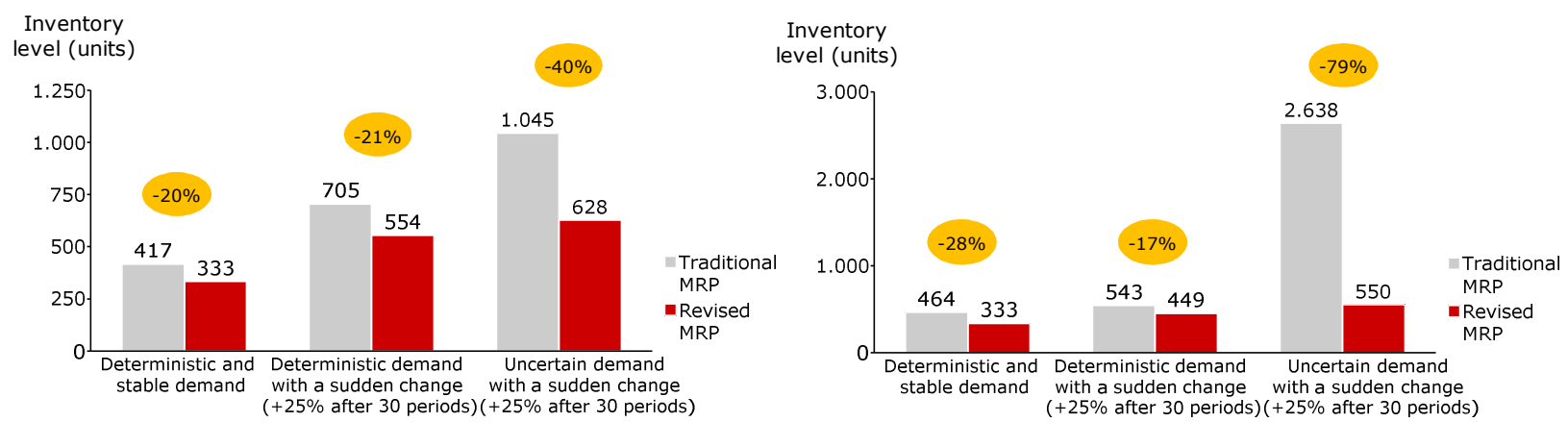

Figure 6: Average stock level along the supply chain - comparison between traditional MRP and Rev MRP, with POQ (left) and EOQ (right) lot sizing techniques

The results of the simulations confirmed that Rev MRP:

- smoothes and stabilizes the production order releases at all the echelon levels (clearly visible in the above fig. 2-5 where the Rev MRP pattern order release is more steady);

- drastically reduces the inventory levels along the supply chain (average stock down of $40 \%$ in case of POQ and almost $80 \%$ in case of EOQ);

- eliminates the need of stockpiling in up-stream echelons, thereby allowing to use smaller warehouses, with less logistic costs for the whole supply chain.

\section{Conclusions and future research}

This paper proposes a new approach to reduce the MRP nervousness which outperformed the traditional MRP in complex supply chains and "real external conditions" (high level of uncertainty on gross requirements).

This work opens several themes for future research:

- simulation of the new approach in different scenarios (different delivery lead times, average demands, standard deviations, more articulated supply chain, ...);

- cost/benefit analysis evaluation;

- test on the field, with manufacturing companies' data;

- development of new features (e.g. the possibility of synchronizing the activities of adjacent echelons, to further reduce the inventory levels by slashing the operating stocks). 


\section{References}

[1] Orlicky J. in: Material Requirements Planning: The New Way of Life in Production and Inventory Management (McGraw-Hill, New York 1975)

[2] Na h., Lee h., Park j. in: A new approach for finite capacity planning in MRP environment, Volume 257/2008, IFIP Advances in Information and Communication Technology (2008)

[3] Zijm w.h.m., Buitenhek r. in: Capacity planning and lead time management, International Journal of Production Economics 46-47 (1996), pp.165-179

[4] Enns s.t. in: MRP performance effects due to forecast bias and demand uncertainty, European Journal of Operational Research 138 (2002), pp. 87-102

[5] Yeung j.h.y., Wong w.c.k. and Ma 1. in: Parameters affecting the effectiveness of MRP systems: a review, International Journal of Production Research 36 (1998), pp. 313-331

[6] Hautaniemi p, Pirttila t. in: The choice of replenishment policies in an MRP environment, Int. J. Prod. Econ. 59 (1999), pp. 85-92

[7] Whybark, Williams in: MRP under uncertainty, Decision Science 7 (1996), p. 35-51

[8] Buzacott, Shanthinkumar in: Safety Stock versus Safety Time in MRP Controlled Production Systems, Management Science, Vol. 40, No. 12 (1994)

[9] Lee t. s., Everett e. in: Forecasting Error Evaluation in Material Requirements Planning (MRP) Production-Inventory Systems, Management Science Vol. 32 No. 9, (1986), pp. 11861205

[10] Vollman b., Whybark j. in: Manufacturing Planning and Control for Supply Chain Management, McGraw-Hill Edition (2005)

[11] Donselaar k.h., Gubbels b.j. in: How to release orders in order to minimise system inventory and system nervousness?, International Journal of Production Economics 78 (2002), pp. 335343

[12] Chen f., Drezner z., Ryan j. k., Simchi-levi d. in: Quantifying the Bullwhip effect in a Simple Supply Chain: The Impact of Forecasting, Lead times, and information, Management Science Vol. 46 no. 3 (2000) pp. 436-443

[13] Lee h.l., Padmanabhan v., Seungjin w. in: The Bullwhip Effect in Supply Chains, Sloan Management Review/Spring (1997);

[14] Forrester j in: Industrial Dynamics: a Major Break Though for Decision-Makers, Harvard Business Review 36 (1958);

[15] Steele d. in: The nervous MRP System: how to do battle, Production and Inventory Management, fourth quarter (1975) pp. 83-89;

[16] Wemmerlov u. in: Design Factors in MRP systems: a limited survey, Production and Inventory Management Fourth quarter (1979), pp. 15-35;

[17] Mather h. in: Reschedule the schedules you just scheduled - Way of life for MRP? Journal of Production and Inventory Management vol. $181^{\text {st }}$ quarter (1977), pag. 60-79;

[18] Iannone R., Lambiase A., Miranda S., Riemma S. in: Performance improvement of a supply chain network with on-line management of backward scheduling: a simulation study Flexible Automation and Intelligent Manufacturing, Proceedings $16^{\text {th }}$ International conference (2006);

[19] Blackburn j.d., Kropp d. h., Millen r. a. in: A comparison of strategies to dampen nervousness in MRP systems, Management Science Vol. 32 No. 4 (1986);

[20] Carlson r.c., Beckman s.l. and Kropp d.h. in: The effectiveness of extending the horizon in rolling production scheduling, Decision Science 13 (1982) pp. 129-146;

[21] Inderfurth k. in: Nervousness in inventory control: analytical results, OR Spektrum 16, (1994), pp. 113-123;

[22] Segerstedt a. in: Formulas of MRP, International Journal Production Economics 46-47, (1996) pp. 127-136; 